\title{
Acid-base changes associated with respiratory acclimatization to altitude
}

\author{
J. S. Milledge \\ M.B., Ch.B., M.D., F.R.C.P. \\ Clinical Research Centre, Northwick Park Hospital, Watford Road, Middlesex HA1 3UJ
}

\begin{abstract}
Summary
The respiratory changes associated with chronic hypoxia are described. The possible biochemical mechanisms which are responsible for the changes in control of ventilation are discussed and relevant experimental evidence assessed.
\end{abstract}

RESPIRATORY acclimatization is the increase in minute ventilation associated with acclimatization to chronic hypoxia. This is the increase over and above any hyperventilation produced in response to acute hypoxia. This effect is well shown when end tidal $\mathrm{PCO}_{2}$ and $\mathrm{PO}_{2}$ are displayed on an $\mathrm{O}_{2} / \mathrm{CO}_{2}$ diagram. In the classical paper by Rahn and Otis (1949), data on end-tidal gases are collected from the literature for residents at different altitudes and compared with results from subjects acutely exposed to hypoxia. In the latter case no hyperventilation is seen until an equivalent altitude of about $4000 \mathrm{~m}$ is reached, whereas in acclimatized subjects there is a linear reduction in $\mathrm{PCO}_{2}$ from sea level upwards so that at $4000 \mathrm{~m}$ there is a difference of $10-12$ $\mathrm{mmHg}(1.3-1.6 \mathrm{kPa}) \mathrm{PCO}_{2}$ indicating an increase in ventilation of over $50 \%$.

The importance to the oxygen economy of the subject of this hyperventilation can be seen if we examine the $\mathrm{O}_{2}$ transport system from air through the body into the tissues. At each step there is a loss of $\mathrm{Po}_{2}$. At sea level the loss from trancheal $\mathrm{Po}_{2}$ to alveolar is of the order of $50 \mathrm{mmHg}(6.7 \mathrm{kPa})$. This can be reduced by hyperventilation. At $5800 \mathrm{~m}$ where the barometric pressure is half that at sea level, ventilation is approximately doubled and this gradient reduced to $25 \mathrm{mmHg}(3 \cdot 3 \mathrm{kPa})$.

This hyperventilation resulting in a reduction of resting $\mathrm{PCO}_{2}$ indicates that the setting for the $\mathrm{CO}_{2}$ chemostat appears to be changed to a lower threshold and this can be documented by carrying out ventilation $/ \mathrm{CO}_{2}$ response tests at sea level and after acclimatization to altitude. If these $\mathrm{CO}_{2}$ response curves are carried out at a number of different oxygen levels, we get a family of response curves which appear to originate approximately at a single point on the $\mathrm{CO}_{2}$ axis. The effect of acclimatization is to shift this whole fan of curves to the left so that it originates at a lower $\mathrm{PCO}_{2}$. The slope of the $\mathrm{CO}_{2}$ response at high oxygen is also increased but the effect of hypoxia on the $\mathrm{CO}_{2}$ response does not appear to be significantly affected by acclimatization (Michel and Milledge, 1963).

What is the biochemical mechanism underlying this change in control? It is believed that the sensors

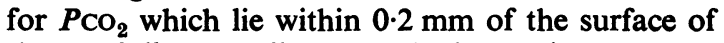
the medulla actually sense hydrogen-ion concentration in their immediate environment, the brain extracellular fluid (ECF), this fluid having an $\left[\mathrm{H}^{+}\right]$ somewhere between the capillary blood and CSF. From the Henderson-Hasselbach equation

$$
\left[\mathrm{H}^{+}\right]=\mathrm{K}_{1} \mathrm{OC} \frac{\mathrm{PCO}_{2}}{\left[\mathrm{HCO}_{3}^{-}\right]}
$$

we understand that the relationship of $\left[\mathrm{H}^{+}\right]$to $\mathrm{PCO}_{2}$ is dependent upon the prevailing $\left[\mathrm{HCO}_{3}^{-}\right]$. Dissolved $\mathrm{CO}_{2}$ passes freely across the blood-brain barrier and into the brain ECF whereas $\left[\mathrm{HCO}_{3}^{-}\right]$ does not, so $\mathrm{PCO}_{2}$ rapidly equilibrates across the various compartments resulting in a change of $\left[\mathrm{H}^{+}\right]$ with changing $\mathrm{PCO}_{2}$. If the $\left[\mathrm{HCO}_{3}^{-}\right]$is reduced, a lower $\mathrm{PCO}_{2}$ must be set to achieve the same $\mathrm{H}^{+}$ at the medullary sensors. This is what appears to happen in respiratory acclimatization, the reduction in $\mathrm{CSF}\left[\mathrm{HCO}_{3}^{-}\right]$resulting in a resetting at a lower level of the $\mathrm{CO}_{2}$ chemostat. The increase in the slope of $\mathrm{CO}_{2}$ response is probably due to the $\left[\mathrm{H}^{+}\right]$ sensors responding to $\log$ changes in $\left[\mathrm{H}^{+}\right]$, i.e. to pH rather than to linear changes in $\left[\mathrm{H}^{+}\right]$and a change of $1 \mathrm{mmHg}(0.13 \mathrm{kPa}) \mathrm{PCO}_{2}$ from 20 to 21 $\mathrm{mmHg}$ has therefore twice the effect as from 40 to $41 \mathrm{mmHg}(5.5 \mathrm{kPa})$.

What is the mechanism for the reduction in CSF $\left[\mathrm{HCO}_{3}^{-}\right]$? The diagram shows on the left the classical pathway for reduction in $\mathrm{CSF}\left[\mathrm{HCO}_{3}^{-}\right]$. Hypoxia stimulates the peripheral chemoreceptors, principally the carotid body, which in turn stimulates the respiratory centre causing hyperventilation. Thus, $\mathrm{Pa}, \mathrm{CO}_{2}$ falls and plasma $\mathrm{pH}$ rises, the kidneys start excreting $\left[\mathrm{HCO}_{3}^{-}\right]$in the urine and plasma $\left[\mathrm{HCO}_{3}^{-}\right]$ falls. A gradient develops for $\left[\mathrm{HCO}_{3}^{-}\right]$across the 
blood-brain barrier and $\mathrm{CSF}\left[\mathrm{HCO}_{3}^{-}\right]$passes out slowly down this gradient.

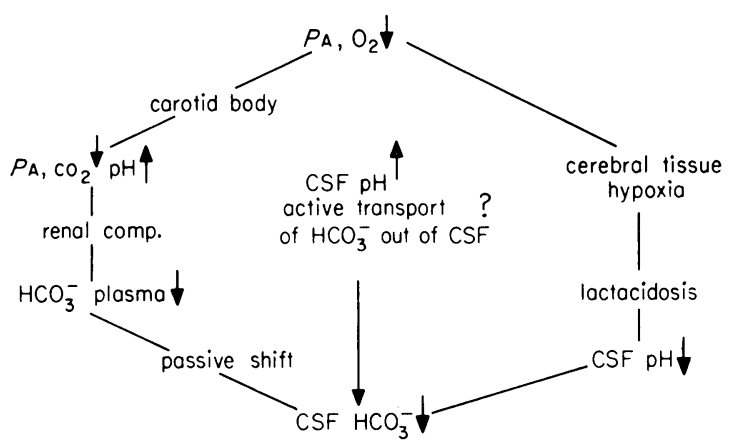

FIG. 1. Mechanisms of reduction in $\mathrm{CSF}\left[\mathrm{HCO}_{3}^{-}\right]$

In 1963 Severinghaus et al. reported that early in acclimatization to altitude their subjects had a restoration of their CSF pH before that in the plasma and to explain this they proposed that there was active transport of $\left[\mathrm{HCO}_{3}^{-}\right]$out of the CSF against the gradient. This was an important paper in that it stimulated a great deal of work in an attempt to prove or disprove this hypothesis. It seems fair to say that the present concensus of opinion is against the necessity of such an hypothesis.

On the right of the diagram is an alternative pathway to $\mathrm{CSF}\left[\mathrm{HCO}_{3}^{-}\right]$reduction. Cerebral tissue hypoxia results in a degree of change of cerebral metabolism from aerobic or anaerobic pathways resulting in the production of lactic acid and other acid metabolites. The $\left[\mathrm{H}^{+}\right]$thus produced titrates the $\mathrm{CSF}\left[\mathrm{HCO}_{3}^{-}\right]$leading to a reduction in its level. This certainly happens to some extent on exposure to hypoxia as has been elegantly shown by Alexander et al. (1968) but the question is how important is it? Severinghaus et al. (1963) considered it unimportant since the lactate increase in the CSF was only about $1 \mathrm{mmol}$ whereas the $\left[\mathrm{HCO}_{3}^{-}\right]$ reduction was 4-5 mmol. However, since lactic acid dissociates in the cell and the 2 ions are then passed out of the cell to ECF to CSF and out into the blood with probably very different rates at each stage, there is no reason to expect a simple stoichiometric relationship between their 2 concentrations in the CSF.

There are 3 pieces of evidence indicating that, at least, under certain circumstances, this direct pathway linking hypoxia to $\mathrm{CSF}\left[\mathrm{HCO}_{3}^{-}\right]$reduction is important:

(1) Sherpas (Milledge and Lahiri, 1967) and Andean natives to high altitude (Severinghaus, Bainton and Carcelen, 1966) have been shown to have very little ventilatory hypoxic response, that is the $\mathrm{CO}_{2}$ response curves at different $\mathrm{PO}_{2} \mathrm{~S}$ lie virtually on top of each other. Also changing the inspired $\mathrm{PO}_{2}$ when exercising has little effect on minute ventilation (Lahiri et al., 1967) and yet these people show similar respiratory acclimatization as judged by resting end-tidal $\mathrm{PCO}_{2}$ and, indeed, their $\mathrm{CSF}\left[\mathrm{HCO}_{3}^{-}\right.$] is actually lower than that of lowlanders at the same altitude (Lahiri and Milledge, 1967).

(2) Eger et al. (1968) measured ventilatory $\mathrm{CO}_{2}$ response before and after an 8-hr period of voluntary hyperventilation. During the 8 -hr period on one occasion they breathed air and on another, a low oxygen mixture. Keeping their end-tidal $\mathrm{PCO}_{2}$ $10 \mathrm{mmHg}(1.3 \mathrm{kPa})$ below normal they found that on air the $\mathrm{CO}_{2}$ response curve was shifted $4 \mathrm{mmHg}$ $(0.53 \mathrm{kPa})$, to the left whilst with hypoxia it was shifted $8 \mathrm{mmHg}(1.06 \mathrm{kPa})$, showing that hypoxia had an effect independent of any change in $\mathrm{PCO}_{2}$.

(3) Sørensen and Mines (1970) showed that goats who had had their carotid bodies denervated so that on exposure to acute hypoxia actually had their respiration depressed, nevertheless showed respiratory acclimatization on being taken to high altitude. In a companion study (Sørensen, 1970) it was shown that rabbits whose peripheral chemoreceptors were denervated had a reduction of CSF $\left[\mathrm{HCO}_{3}^{-}\right]$similar to that of controls when taken to altitude.

It has also been shown that in fact the CSF pH is not so very closely regulated as had previously been thought. Indeed, Dempsey, Forster and Do Pico (1974) from consideration of the time course of the changes in CSF, $\mathrm{pH}$ and arterial $\mathrm{PCO}_{2}$ cast doubt on the importance of $\mathrm{CSF}\left[\mathrm{H}^{+}\right]$in the control of breathing at altitude, especially the more long-term acclimatization, i.e. from 3-5 days to 2-3 weeks. It seems difficult to explain the further increase in breathing during this time as being due to acid-base changes, and changes in the modifying effect of cortical control may be involved. Evidence for such control is to be found in the effect of sleep on respiratory control and from the work of Tenney et al. (1971) on cats, whose blunted hypoxic response could be restored by section below the diencephalon. However, Davies (1978) is of the opinion that in the early stages of acclimatization, i.e. up to $3 \mathrm{hr}$, changes in ECF $\left[\mathrm{H}^{+}\right]$account for the changes in respiration but only by placing the ECF $\left[\mathrm{H}^{+}\right]$nearer the blood than the $\mathrm{CSF}\left[\mathrm{H}^{+}\right]$. The present author and his colleagues found that the CSF $\mathrm{pH}$ of acclimatized lowlanders at $4880 \mathrm{~m}$ was $7 \cdot 374$, and that of Sherpas at a similar altitude was 7.328 (Lahiri and Milledge, 1967), and in Andean natives at $4300 \mathrm{~m}$ the CSF pH was 7.295 (Sørensen and Milledge, 1971). 
It would seem that in achieving a very similar degree of respiratory acclimatization one should picture a wide spectrum of proportion of contribution from central and peripheral drives for different subjects. The lowlander with a brisk peripheral hypoxic drive will tend to have a more alkaline CSF $\mathrm{pH}$ whilst the highlander with less peripheral drive will have a more acid $\mathrm{pH}$ and get his 'drive' from that source whilst the denervated animal must derive its 'drive' wholly from an even more acid $\mathrm{pH}$.

Have these changes anything to do with acute mountain sickness (AMS), the subject of the symposium? Two hints that they may play some part are provided by: (1) the time course of these changes which is similar to that of AMS. The main changes of respiratory acclimatization take place in the first $48 \mathrm{hr}$ after arrival at altitude which is when AMS tends to be worse; and (2) the finding by Sutton et al. (1976) who showed that there was a quite good correlation between the severity of AMS and the rate of respiratory acclimatization as judged by the reduction in $\mathrm{PCO}_{2}$. This only held for the first day after arrival at altitude and was thereafter largely lost. Also, there was no correlation with $\mathrm{PO}_{2}$ or $\mathrm{pH}$. The finding of this correlation is in line with the impressions of climbers that voluntary hyperventilation is of some benefit in relieving the symptoms of AMS. It may be that the difference between individuals in the degree of mountain sickness may be found in the different rates of respiratory acclimatization between one subject and another.

\section{References}

Alexander, S.C., Smith, T.C., Strobel, G., Stephen, G.W. \& Wollman, H. (1968) Cerebral carbohydrate metabolism of man during respiratory and metabolic alkalosis. Journal of Applied Physiology, 24, 66.

DAviEs, D.G. (1978) Evidence for cerebral extracellular fluid $\left[\mathrm{H}^{+}\right]$as a stimulus during acclimatization to hypoxia. Respiration Physiology, 32, 167.
Dempsey, J.A., Forster, H.V. \& Do Pico, G.A. (1974) Ventilatory acclimatization to moderate hypoxemia in man. The role of spinal fluid $[\mathrm{H}+]$. Journal of Clinical Investigation, 53, 1091.

Eger, E.I., Kellogg, H., Mines, A.H., Lima-Ostos, M., Morrill, C.G. \& KeNT, D.W. (1968) Influence of $\mathrm{CO}_{2}$ on ventilatory acclimatization to altitude. Journal of Applied Physiology, 24, 607.

LAHIRI, S. \& Milledge, J.W. (1967) Acid-base in Sherpa altitude residents and lowlanders at $4880 \mathrm{~m}$. Respiration Physiology, 2, 323.

Lahiri, S., Milledge, J.S., Chattopadhyay, H.P., BhattachaRYya, A.K. \& Sinha, A.K. (1967) Respiration and heart rate of Sherpa highlanders during exercise. Journal of Applied Physiology, 23, 545.

Michel, C.C. \& Milledge, J.S. (1963) Respiratory regulation in man during acclimatization to high altitude. Journal of Physiology, 168, 631.

Milledge, J.S. \& LAHIRI, S. (1967) Respiratory control in lowlanders and Sherpa highlanders. Respiration Physiology, $2,310$.

RAHN, H. \& OTIS, A.B. (1949) Man's respiratory response during and after acclimatization to high altitude. American Journal of Physiology, 157, 445.

Severinghaus, J.W., Bainton, C.R. \& Carcelen, A. (1966) Respiratory insensitivity to hypoxia in chronically hypoxic man. Respiration Physiology, 1, 308.

Severinghaus, J.W., Mitchell, R.A., Richardson, B.W. \& SiNGER, M.M. (1963) Respiratory control at high altitude suggesting active transport regulation of CSF pH. Journak of Applied Physiology, 18, 1155.

Sørensen, S.C. \& Mines, A.H. (1970) Ventilatory response to acute and chronic hypoxia in goats after sinus nerve section. Journal of Applied Physiology, 28, 832.

Sørensen, S.C. (1970) Ventilatory acclimatization to hypoxia in rabbits after denervation of peripheral chemoreceptors. Journal of Applied Physiology, 28, 836.

Sørensen, S.C. \& Milledge, J.S. (1971) Cerebrospinal fluid acid-base composition at high altitude. Journal of Applied Physiology, 31, 28.

Sutton, J.R., Bryan, A.C., Gray, G.W., Horton, E.W., RebuCK, A.S., Woodley, W., Rennie, I.D. \& Houston, C.S., (1976) Pulmonary gas exchange in acute mountain sickness. Aviation, Space and Environmental Medicine, 47, 1032

Tenney, S.M., Scotto, P., Ou, L.C., Barlett, D. \& Remmers, J.E. (1971) In: High Altitude Physiology: Cardiac and Respiratory Aspects. Cibà Symposium, p. 89. Churchill Livingstone, London.

\section{Discussion}

DR J. H. COOTE: I assume from the Rahn-Otis plot that acclimatized subjects would tend to hyperventilate earlier as judged by their alveolar $\mathrm{PCO}_{2}$. How does this equate with the blunted hypoxic response?

DR J. S. Milledge: The answer is that they have a more acid CSF and a slightly lower CSF bicarbonate so they get their respiratory drive from that rather than from the periphery.
DR C. S. Houston: Riley postulated that the logical place for a respiratory centre would be in the pulmonary artery. It has never been demonstrated but Riley still thinks that it should be there.

DR Milledge: The incentive to discover a pulmonary artery sensor is to try to explain the hyperpnoea of exercise. I don't think that it would help much in relationship to altitude. 